\title{
LOS MICROORGANISMOS HALÓFILOS Y SU POTENCIAL APLICADO EN BIOTECNOLOGÍA
}

\author{
INMACULADA MESEGUER SORIA* \\ DPTO. DE PRODUCCIÓN VEGETAL Y MICROBIOLOGIA. UNIVERSIDAD MIGUEL HERNANDEZ DE ELCHE \\ * AVDA, DE la UNIVERSIDAD SIN, EDIFICIO TORREGAITÁN, 03202 ElCHE (ALICANTE) ESPAÑA
}

\section{AMBIENTES HIPERSALINOS}

La sal común ( $\mathrm{NaCl}$, en elevadas concentraciones, es considerada generaimente como un inhibidor del crecimiento microbiano, por lo que ha sido ampliamente utilizada como un aditivo para la conservación de alimentos, curtido de pieles, etc. Sin embargo, existe gran cantidad de microorganismos, llamados halófilos, que son capaces de vivir en presencia de altas concentraciones de sal es decir en ambientes hipersalinos (1). Esto es posible porque a lo largo de su evolución, los microorganismos halófilos han desarrollado diversas propiedades 0 mecanismos de adaptación a dichos ambientes, hasta tal punto que más que de una gran afinidad realmente se trata de una gran dependencia por la sal.

Los ambientes hipersalinos acuáticos en los que la concentración de sal supera la del agua de mar (3.5\% de sales totales) pueden ser de origen natural, como el Gran Lago Salado en Estados Unidos o el Mar Muerto en Israel. Pero también pueden ser de origen artificial como las salinas construidas por el hombre para la obtención de sal. Por otra parte, la mayoria de las salinas están ubicadas en la costa, ya que la sal se obtiene por la evaporación del agua de mar. Tal es el caso de las salinas de Bras del Port en Santa Pola, Alicante (España). Sin embargo existen también salinas terrestres, en las que las salmueras o aguas saladas, proceden de fuentes, róos o lagos. Un ejemplo de este tipo son las salinas de Maras en la provincia de Urubamba, Cusco (Perú). Tanto éstas como las anteriores son salinas denominadas de «estanque múltiple», debido a que las salmueras se distribuyen en un conjunto de balsas de evaporación. Este tipo de salinas son especialmente útiles para realizar estudios sobre la diversidad de los microorganismos halóflos, ya que en ellas encontramos multitud de ambientes con distintos grados de salinidad.

\footnotetext{
* Emaik meseguer@umhes
}

\section{MICROORGANISMOS HALÓFILOS}

Aunque el estudio de los microorganismos halofilos comenzó hace cerca de un siglo, el mayor impulso en el conocimiento de estos microorganismos ha tenido lugar en los últimos 25 años. Actualmente sabemos que existe una gran diversidad de microorganismos halófilos de los que apenas se han aislado y estudiado un pequeño porcentaje. Se trata pues de un campo de estudio cuya exploración apenas se ha iniciado.

El têrmino «halófilo» viene del griego, donde «halo» es "sal" $y$ "filo" es "amante de", es decir, significa «amante de la sal». Sin embargo no todos los microorganismos halófilos tienen los mismos requerimientos de sal, por lo que tienden a agruparse en función del rango de sales que necesitan para tener un crecimiento óptimo. El criterio no está universalmente unificado pero por termino medio se consideran dos tipos de halófilos propiamente dichos (2):

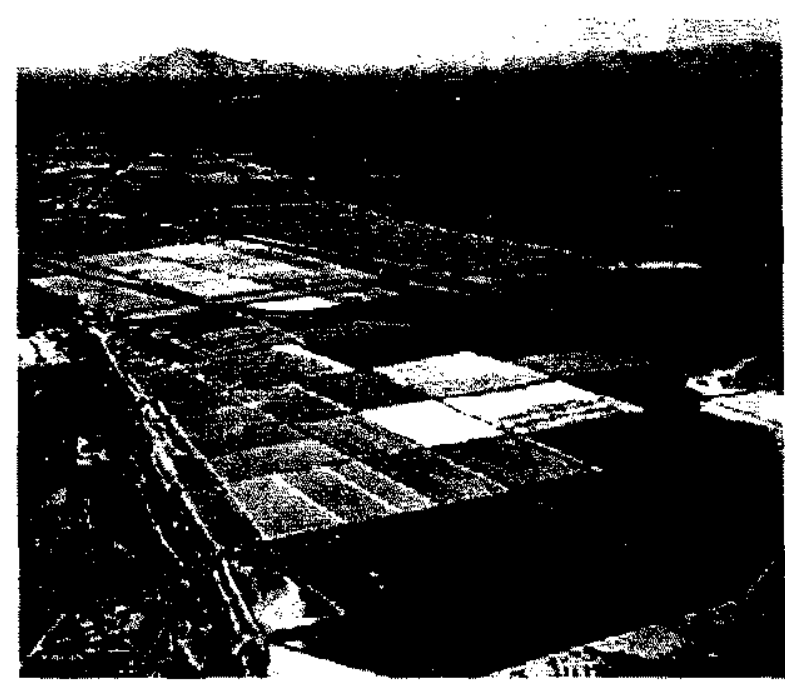

Figura 1. Vista aérea de las Salinas Bras del Port en Santa Pola (Alicante) España. Un ejemplo característico de salinas de estanque multiple. La tonalidad rojiza es debida a la presencia de microorganismos halófilos pigmentados. 
- Halófilos moderados, cuando presentan un crecimiento óptimo en medios que contienen entre el 5 y $20 \%$ de $\mathrm{NaCl}$.

- Halófilos extremos, si crecen óptimamente en medios que presentan una concentración entre el $20-30 \%$ de $\mathrm{NaCl}$

No obstante, algunos autores también utilizan el término de halófilos débiles para designar a aquellos microorganismos que viven en ambientes con una salinidad próxima a la del agua de mar (óptimo entre $2-5 \%$ de $\mathrm{NaCl}$ ). Adicionalmente existe un grupo de organismos denominados halotolerantes, que aunque habitualmente viven mejor sin sal, admiten cierta concentración de ella en su medio ambiente.

Los ambientes hipersalinos, son en general medios inhóspitos para los seres vivos. El problema más importante con que se encuentran los microorganismos en este tipo de ambientes, es la pérdida del agua citoplasmática debida a la elevada osmolaridad del medio. Para combatir este problema los halófilos moderados y extremos, han desarrollado un mecanismo que consiste en acumular en su citoplasma una sustancia para regular su turgencia interna sin producir inhibición del metabolismo celular. Dicha sustancia, que se conoce como soluto compatible, puede tener distinta procedencia dependiendo del tipo de microorganismo (1). En unos casos el soluto compatible es sintetizado por el microorganismo (azucares, polialcoholes, aminoácidos, etc.). En otros, se trata de sustancias o iones presentes en el medio (betainas, $\mathrm{K}^{+}$) y acumulados activamente en el interior celular gracias a mecanismos de transporte de membrana.

A su vez, la presencia de altas concentraciones de soluto compatible en el citoplasma, como en el caso del $\mathrm{K}^{+}$, que llega a alcanzar concentraciones tan elevadas como 5M, ha obligado a estos microorganismos a sufrir cambios profundos en su composición y fisiología. El conjunto de los dispositivos que capacitan a los organismos halófilos para vivir en condiciones de elevada salinidad reciben el nombre de mecanismos de haloadaptación. En los ambientes hipersalinos mencionados, coexisten microorganismos halófilos pertenecientes a grupos filogenéticos muy diferentes. Sin embargo su distribución no es precisamente homogénea sino que existe un claro predominio de unos grupos frente a otros dependiendo del grado de salinidad del medio. Para clarificar mejor esta afirmación conviene repasar la situación actual en relación con la clasificación de los seres vivos.

\section{FILOGENIA DE LOS SERES VIVOS}

Desde los comienzos de la Biología como Ciencia, se ha tratado de clasificar a los seres vivos para facilitar su estudio. Los criterios de clasificación que se utilizaron al principio eran exclusivamente morfológicos, basados en la simple observación. Esto no suponía grandes dificultades mientras se trataba de seres visibles macroscópicamente como los animales y las plantas. Sin embargo, el descubrimiento de los microorganismos, significó un reto para los taxonomistas debido a la enorme dificultad de discriminar morfológicamente a los microorganismos procariotas. Así pues se hizo necesario recurrir a nuevos criterios como la estructura interna, composición y fisiología. Tales criterios además se han ido modificando en función de las metodologías científicas disponibles en cada época. En los últimos 50 años, el desarrollo de las técricas de Biología Molecular, ha revolucionado multitud de campos de estudio en la Biología y en particular, en taxonomía, ha influido profundamente. Durante años se buscó una molécula ampliamente distribuida entre todos los seres vivos que permitiera establecer un nuevo criterio evolutivo, es decir, un "cronómetro molecular» que permitiera elaborar árboles filogenéticos que incluycran a todos los seres vivos para establecer el parentesco evolutivo entre ellos. En 1977, Woese y Fox (3) encontraron el mejor cronómetro molecular descrito hasta la fecha, el RNA ribosomal y, basándose en la secuencia de esta molécula, propusieron una nueva clasificación organizada en tres ramas que posteriormente se ha ido perfilando y consolidando.

Así, los seres vivos se distribuyen filogenéticamente en tres grupos o dominios:

- Bacteria: incluye a todos los microorganismos procariotas del tipo de las «bacterias», también denominadas «eubacterias» o «bacterias auténticas».

- Archaea: incluye a todos los microorganismos procariotas del tipo de las «arqueas», también denominadas "arqueobacterias».

- Eukarya: incluye a todos los organismos eucariotas también conocidos como "organismos superiores», es decir, algas, hongos, protozoos, vegetales y animales.

Entre los microorganismos halófilos estudiados hasta la fecha, existen individuos pertenecientes a los tres dominios: Eukarya, Bacteria y Archaea. Sin embargo, como mencionamos arriba, dependiendo de la concentración de sal del medio, la abundancia de unos a otros varía considerablemente. Así en los ambientes en los que la salinidad es extrema, las arqueas son los microorganismos más abundantes. A medida que la concentración es más moderada, las bacterias van aumentando en proporción, siendo con mucho mayoritarias cuando la concentración de sal es inferior al $10 \%$. Por su parte, los microorganismos eucariotas son en general escasos o minoritarios cuando la concentración de sal supera cl 5\%.

Las arqueas descubiertas hasta la fecha, entre otros aspectos, tienen en común el de habitar en ambientes considerados fisiológicamente extremos (hipertermófilos, hipersalinos, anaeróbicos, etc.). Aunque ello conlleva ciertas dificultades con respecto a su estudio (aislamiento, cultivo, etc.), de entre todas, son las arqueas halófilas extremas o haloarqueas las que ofrecen mayores ventajas y facilidades para su manipulación. 
Las membranas de las arqueas son únicas en la naturaleza, ya que están constituidas por un tipo exclusivo de lípidos que presentan hidrocarburos de cadena ramificada unidos al glicerol mediante endaces «éter» en lugar de ácidos grasos conectados al glicerol por enlaces «éster".

Las arqueas poseen muchos rasgos en común con las bacterias. Quizás el más importante sea la arquitectura celular, es decir son células procariotas, con un cromosoma único carente de membrana nuclear. Sin embargo un aspecto diferencial entrc arqueas y bacterias es la composición de la pared celular, ya que las paredes de arqueas carecen de peptidoglicano. Algunas poseen un componente parecido llamado pseudomureína, pero la mayoría poseen capas «S» formadas por proteínas o glicoprotéínas.

Además poseen muchos otros aspectos que las diferencian de las bacterias e incluso muestran mayor proximidad filogenética con los eucariotas como es el caso de la RNA polimerasa dependiente de DNA, la sensibilidad a ciertas drogas, etc. Así el propio Carl Woese, su descubridor, afirma "Archaea are honorary eukaryotes with prokaryotic cell organization». Esta afirmación tiene especial relevancia desde el punto de vista aplicado, ya que potencialmente podríamos obtener sustancias producidas por arqueas que pudieran tener actividad sobre un organismo eucariota como el hombre. Es decir, las arqueas podrian suponer una nueva fuente de sustancias naturales con actividad farmacológica.

El potencial científico que el descubrimiento de las arqueas supone, ha llevado a numerosos grupos investigadores a interesarse por su estudio. Sin embargo y en comparación con los otros dominios, las arqueas son un grupo de organismos prácticamente desconocido y probablemente estamos todavía muy lejos de apreciar y/o valorar la verdadera importancia de su hallazgo y los beneficios y aplicaciones que su conocimiento puede reportarnos en el futuro.

\section{MICROORGANISMOS HALÓFILOS MODERADOS}

Fntre los microorganismos de este grupo no encontramos arqueas, ya que aunque algunas especies son capaces de vivir al $12 \%$ de sales totales, su óptimo está por encima del $20 \%$.

Tampoco encontramos muchos representantes eucariotas salvo algunas algas (p.e. Dunaliella viridis), hongos filamentosos (p.e. Trimmatrostroma salinum), levaduras (p.e. Hortaea werneckii) y protozoos (p.e. Bodo sp., Fabrea salina, etc).

Mucho más abundantes son sin embargo las bacterias halófilas moderadas (4), de las que hay una gran diversidad que muestran metabolismos muy variados. Entre las fototróficas podríamos mencionar a las cianobacterias planctónicas y formadoras de tapetes microbianos (microbial mats) y otras bacterias fototróficas anaerobias del grupo de las bacterias rojas y verdes del azufre (p.e. Ectothiorhodospira spp.) y no del azufre (p.e. Chromatium spp.). También encontramos bacterias gram negativas anaerobias (p.e. Haloanaerobacter spp.), algunas de ellas metanógenas (como Methanohalophilus spp.) y aerobias o facultativas (como algunas especies de los géneros Halomonas, Cromohalobacter, Salinovibrio, Pseudomonas, etc). También hay muchas especies de bactcrias gram positivas pertenecientes a varios géneros como Halobacillus, Bacillus, Marinococcus, etc. y algunos actinomicetes (p.e. Actinopolispora halophila).

\section{MICROORGANISMOS HALÓFILOS EXTREMOS}

Recientemente se han aislado algunas cepas de bacterias del género Salinibacter (5), pero por el momento, la inmensa mayoría de los microorganismos halófilos extremos aislados hasta el momento, son procariotas pertenecientes al dominio Archaea. Entre las arqueas halófilas existen microorganismos pertenecientes a tres familias, siendo la más representativa de ellas la Halobacteriaceae, también conocidas vulgarmente como halobacterias y más recientemente como haloarqueas.

Al principio se creyó que esta familia estaba constituida por un grupo muy reducido de especies, sin embargo en los últimos años se ha comprobado que esto no era así. Las imágenes de microscopía de muestras procedente de los cristalizadores de las salinas Bras del Port, donde predominan las haloarqueas, muestran una gran variedad de morfologías, indicando una amplia diversidad de microorganismos, la mayoría de los cuales no se han logrado todavía cultivar.

Actualmente y a pesar de que solo conocemos una pequeña proporción de ellos, ya se han descrito al menos 15 géneros con más de 44 especies (1). Una de las especies mejor conocida, por ser una de las primeras aisladas es el Halobacterium salinarum, del que ya se ha obtenido el genoma completo.

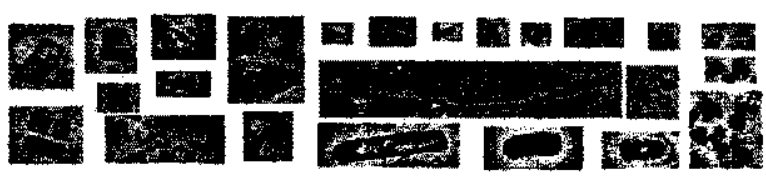

Figura 2: Morfología de microorganismos halofilos presentes en una muestra de agua de un cristalizador de las salinas Bras del Port, Santa Pola (Alicante). Todas las imágenes están tomadas a 1000 aumentos, por $l o$ que los tamaños relativos son los que se muestran en las imágenes. 
Por pertenecer al dominio Archaea, las haloarqueas poseen una serie de características peculiares ya mencionadas. Sin embargo, lo que resulta más llamativo de estos microorganismos es probablemente su capacidad para vivir en las condiciones extremas de los ambientes hipersalinos, hasta 3-4 Molar de $\mathrm{NaCl}$ y bajo una intensa radiación solar, condiciones en las que prácticamente ningún otro organismo es capaz de sobrevivir. Las haloarqueas, son por tanto los halófilos mas extremos y su viabilidad está condicionada a una concentración salina mínima, por debajo de la cual las células se lisan. Esto implica haber desarrollado mecanismos de haloadaptación únicos que se manifiestan en la naturaleza de sus componentes, su metabolismo y su fisiología.

Es factible, por tanto, suponer la existencia de componentes celulares o productos del metabolismo con actividades biológicas que no puedan encontrarse en otros seres vivos. Pero al mismo tiempo no hemos de perder de vista la proximidad filogenética de estos microorganismos con los organismos superiores con los que pueden mostrar cierta similitud y/o convergencia.

Las haloarqueas poseen en su membrana celular pigmentos carotenoides que les proporciona protección frente a la fuerte irradiación solar a que están sometidas (1). Cuando se cultivan en el laboratorio producen colonias de diversas tonalidades rojizas, rosas o anaranjadas, dependiendo de las especies y las condiciones de cultivo. La membrana celular que contiene estos pigmentos se conoce por ello como «membrana roja». En ambientes tales como las salinas, donde estos microorganismos se encuentran en elevadas concentraciones, el agua puede llegar a adquirir tonalidades muy intensas (desde el anaranjado al rojo).

Además de los pigmentos carotenoides algunas especies de haloarqueas producen otro tipo de pigmentos, «retinal proteins» (6), entre los cuales destaca la bacteriorrodopsina (bacteriorhodopsin) y la halorrodopsina (halorhodopsin) que permiten al microorganismo utilizar la energía luminosa para generar gradientes de protones y cloruro respectivamente. Estos gradientes son utilizados por el microorganismo para realizar distintos procesos bioenergéticos. También existen otras, «sensory rhodopsins", que intervienen en mecanismos de fototaxis. Todos estos pigmentos están constituidos por un tipo de proteínas asociadas con una molécula de retinal y se localizan en la membrana citoplasmática. Pero mientras la halorrodopsina y las sensory rhodopsins se encuentran dispersas por la membrana, las moléculas de bacteriorrodopsina se asocian entre sí, formando a modo de parches que toman de color púrpura. Así pues en estos microorganismos encontramos:
- Membrana roja: compuesta esencialmente por lípidos y proteínas. En ella se localizan los pigmentos carotenoides, halorrodopsina, sensory rhodopsins y el resto de los componentes habituales de la membrana (ATPasa, transportadores de sustancias, transporte electrónico, etc.).

- Membrana púrpura: compuesta casi exclusivamente por bacteriorrodopsina y lípidos.

Un aspecto muy llamativo de las haloarqueas, y todavía muy poco estudiado, es la presencia intracelular de estructuras altamente organizadas conocidas como cuerpos fibrocristalinos, que consisten en haces de microtúbulos que recuerdan a los microtúbulos del citoesqueleto de los eucariotas (7). Además las drogas que inhiben la mitosis de las células eucariotas, también tienen un efecto inhibidor sobre el crecimiento de haloarqueas. Esto puede tener especial interés en relación con el desarrollo de nuevos procedimientos de "screening" para la búsqueda de nuevas drogas antitumorales.

Otra característica general de estos microorganismos es la producción de halocinas que son sustancias equivalentes a las bacteriocinas producidas por bacterias (8). Las halocinas son por tanto productos de naturaleza protéica con actividad antibiótica frente a otras haloarqueas. A este tipo de sustancias se les asigna una función de competencia entre microorganismos que comparten el mismo hábitat.

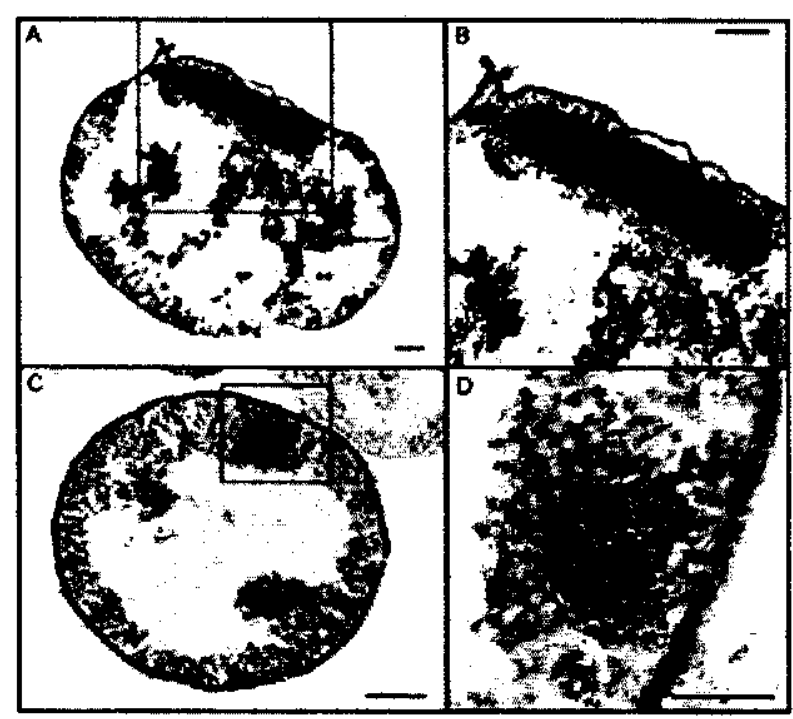

Figura 3. Microscopía electrónica de secciones ultrafinas de células de Halobacterium salinarum en las que se observan secciones longitudinales $(A$ y $B$ ) y transversales ( $C$ y $D)$ de los cuerpos fibrocristalinos. Las barras indicadoras representan 0,1 micra de longitud. 


\section{POTENCIAL APLICADO DE LOS HALÓFILOS}

Al igual que otros microorganísmos, los halófllos son considerados como una fuente potencial de productos de interés aplicado en diversos sectores de las industrias: Alimentaria, Farmacéutica, Cosmética, Química, ctc.

Por otra parte, como resultado de los procesos de haloadaptación y de protección frente al estrés provocado por diversos factores característicos de los ambientes hipersalinos (elevada concentración salina, alta radiación solar, cambios extremos de temperatura, etc), los halófilos han desarrollado una serie de características únicas que suponen toda una amplia gama de productos nuevos con propiedades especiales.

Adicionalmente, los halófilos extremos son mayoritariamente arqueas, que también a su vez poseen unas cualidades exclusivas y otras compartidas con los otros dominios, por lo que podemos encontrar enzimas, inhibidores, etc que proceden de arqueas pero que presentan actividad sobre eucariotas o bacterias.

Con todo, algunas de las aplicaciones que podemos destacar son $(9,10)$ :

1. Bacteriorrodopsina: Debido a sus propiedades fotocrómicas, se perfila como un pigmento con gran futuro en aplicaciones muy diversas como material para elaboración de memorias ópticas, almacenamiento y procesado de información, holografía, moduladores espaciales de luz, etc.

2. Solutos compatibles orgánicos: estabilizadores de biomoléculas y células, antagonistas de sales, agentes protectores de estrés, elc.

3. Biopolimeros

a. Exopolisacáridos: espesantes, emulgentes y gelificantes.

b. Liposomas: transporte de compuestos en medicina y cosmética.

c. Acido poli-g-D-glutâmico (PGA): humectante, espesante, etc.

d. Polihidroxialcanoatos: prótesis, plásticos biodegradables, etc.

4. Enzimas

a. Ilidrolasas: Enzimas como b-galactosidasas, a-amilasas, serina proteasas, etc pueden ser de utilidad en la obtención de ciertos productos en industrias farmacéuticas, químicas, etc.

b. Isomerasas: para el modelamiento, estabilización, desnaturalización y renaturalización de proteinas.

5. Halocinas como el PINHE: protector en el infarto de miocardio (entre otros usos).

6. Vesículas de gas: separación, presentación de antígenos y desarrollo de vacunas.

7. Pigmentos carotenoides: como el b-caroteno, que es un precursor de la vitamina $\mathrm{A}$ y es un aditivo de gran importancia como complementos y colo- rantes de alimentos, en productos cosméticos, como componentes de fármacos, etc.

8. Ácidos grasos poliinsaturados de cadena larga (PUFA): como complementos en dietas para contrarrestar deficiencias en ácidos grasos esenciales.

Así pues es obvio que existe un gran potencial de aplicaciones de interés biotecnológico procedente de los microorganismos halófilos. Algunas de estas aplicaciones están ya en el mercado. Otras o se están estudiando a escala piloto, o están en desarrollo. Seguramente, muchas aún no las conocemos. Pero en los últimos años se está haciendo un gran esfuezo, potenciando los proyectos de investigación destinados a buscar nuevos productos entre microorganismos extremófilos: halófilos, termófilos, psicrofilos, etc, por lo que cabe esperar un futuro muy prometedor en el campo de la biotecnología de estos microorganismos.

\section{REFERENCIAS BIBLIOGRÁFICAS}

1. Oren A. 2002. Halophilic microorganisms and their environments. Kluwer Academic Publishers. Dordrecht/Boston/London.

2. DasSarma S., Arora P. 2002. Halophiles. Encyclopedia of Life Sciences 8:458-466. London: Nature Publishing Group.

3. Woese C., Fox C. 1977. Philogenetic structure of the prokaryotic domain: The primary kingdoms. Proc. Natl. Acad. Sci. USA 74 (11); 5088-5090.

4. Ventosa A, Nieto J. J., Oren A. 1998. Biology of Moderately Halophilic Aerobic Bacteria. Microbiol. Mol. Biol. Rev. 62; 504-544.

5. Anión J., Rosselló-Mora R, Rodriguez-Valera F. y Amann R. 2000. Extremely halophilic bacteria in crystallizer ponds solar salterns. Appl. Environ. Microbiol. 66(7): 3052-3057.

6. Lanyi J. K. 2004. Bacteriorhodopsin. Annu Rev. Physiol. 66: 665-688.

7. Alba I., Torreblanca M., Sánchez M. Colom F., Meseguer I. 2001. Isolation of the fibrocrystalline body from Halobacterum salinarum. A structure present in haloarchaea species. Extremophiles, vol 5:169-175.

8. Torreblanca M., Meseguer I., Ventosa A. 1994. Production of Halocin is a Practically Universal Feature of Archaeal Halophilic Rods. Lett. Appl. Microbiol., vol 19: 201-205.

9. Schiraldi C., Giuliano M., de Rosa M. 2002. Perspectivas on biotechnological applications of Archaea. Archaea, vol 1: 75-86.

10. Margesin R., Schinner F. 2001. Potential of halotolerant and halophilic microorganisms for biotechnology. Extremophiles, vol 5: $73-83$. 